\title{
Uso de aditivos equilibradores de microbiota na alimentação de aves comerciais:
}

\section{Revisão}

Use of microbiota balancing additives in commercial poultry feed: Review

Uso de aditivos para equilibrar la microbiota en los piensos comerciales para aves de corral: Revisión

Dayane Albuquerque da Silva ORCID: https://orcid.org/0000-0001-6243-3969 Universidade Federal Rural de Pernambuco, Brasil E-mail: dayane.albuquerque.ds@gmail.com

Carlos Bôa Viagem Rabello

ORCID: https://orcid.org/0000-0002-5912-162X

Universidade Federal Rural de Pernambuco, Brasil E-mail: carlos.rabello@ufrpe.br

Marcos José Batista dos Santos ORCID: https://orcid.org/0000-0002-6023-3426 Universidade Federal Rural de Pernambuco, Brasil E-mail: marcoszootecnista@gmail.com

Júlio Cézar dos Santos Nascimento ORCID: https://orcid.org/0000-0003-3107-5876 Universidade Federal Rural de Pernambuco, Brasil E-mail: julio.nascimento@ufrpe.br Apolônio Gomes Ribeiro

ORCID: https://orcid.org/0000-0001-6730-0209 Universidade Federal Rural de Pernambuco, Brasil

E-mail: apoloniogomes962@gmail.com

Gabriel Miranda Macambira

ORCID: https://orcid.org/0000-0002-0277-5286

Universidade Federal Rural de Pernambuco, Brasil

E-mail: gabriel.miranda.zootecnia@gmail.com

Helia Sharlane de Holanda Oliveira

ORCID: https://orcid.org/0000-0002-4314-4827

Universidade Federal Rural de Pernambuco, Brasil E-mail: sharlaneho@yahoo.com

Ana Carolina Ferreira dos Santos

ORCID: https://orcid.org/0000-0003-0361-5222

Universidade Federal Rural de Pernambuco, Brasil E-mail: carolufrpe@hotmail.com

Letícia Aline Lima da Silva

ORCID: https://orcid.org/0000-0002-4758-9890 Universidade Estadual de Maringá, Brasil

E-mail: leticiaalinezoo@gmail.com

Maria Aline Alves Mota

ORCID: https://orcid.org/0000-0001-7171-7648 Universidade Federal Rural de Pernambuco, Brasil

E-mail: mariaaline168@gmail.com

Mirelio Ferreira da Silva

ORCID: https://orcid.org/0000-0003-2692-663X Universidade Federal do Ceará, Brasil

E-mail: mireliosilva@gmail.com

Marcos Rafael de Sousa Rodrigues

ORCID: https://orcid.org/0000-0002-8572-8337 Universidade Federal dos Vales do Jequitinhonha e Mucuri, Brasil

E-mail: marcoscrate10@gmail.com

Jéssica Maria dos Santos Silva

ORCID: https://orcid.org/ 0000-0001-5524-9987 Universidade Federal dos Vales do Jequitinhonha e Mucuri, Brasil E-mail: jessicasilva12213@gmail.com 


\begin{abstract}
Resumo
Os antibióticos equilibradores de microbiota vêm sendo utilizados na alimentação animal desde a década de 50, por promoverem benefícios a saúde dos animais, entretanto o uso prolongado desses aditivos desencadeou a problemática da resistência bacteriana, o que levou os órgãos mundiais e nacional (WHO, UE, FDA e MAPA) a proibição de diversos aditivos. Contudo, aves em sistemas industriais são submetidas à ambientes adensados e desafiados, tornando impossível a isenção de compostos na dieta que modulem a microbiota intestinal e consequentemente favoreçam beneficamente a digestibilidade e absorção dos nutrientes da dieta. Neste aspecto a utilização de aditivos equilibradores de microbiota alternativos ao antibiótico como, prebiótico, probiótico e simbiótico tornam-se indispensáveis, por estes serem naturais, não causarem resistência bacteriana e promoverem mútuos benefícios à saúde animal. Com isso, está revisão tem por objetivo elucidar os benefícios dos aditivos equilibradores de microbiota na alimentação de aves poedeiras comerciais, com ênfase nos efeitos produzidos a partir da modulação da microbiota residente. A metodologia adotada foi o estudo descritivo, resultando em uma revisão bibliográfica embasada em artigos científicos mundiais.
\end{abstract}

Palavras-chave: Prebiótico; Probiótico; Resistência bacteriana; Simbiótico.

\begin{abstract}
The microbiota balancing antibiotics have been used in animal feed since the 50's, by promoting health benefits to animals, however, the prolonged use of these additives triggered the problem of bacterial resistance, which led the world and national bodies (WHO, EU, FDA and MAPA) to ban various additives. However, birds in industrial systems are subjected to dense and challenged environments, making it impossible to exempt compounds in the diet that modulate the intestinal microbiota and consequently beneficially favor the digestibility and absorption of nutrients in the diet. In this aspect, the use of microbiota balancing additives alternative to antibiotics, such as prebiotics, probiotics and symbiotics, become indispensable because they are natural, do not cause bacterial resistance and promote mutual benefits to animal health. Thus, this review elucidates the benefits of microbiota balancing additives in feeding commercial laying birds, with emphasis on the effects produced from the modulation of the resident microbiota. The methodology adopted was a descriptive study, resulting in a literature review based on worldwide scientific articles.

Keywords: Prebiotic; Probiotic; Bacterial resistance; Symbiotic.
\end{abstract}

\title{
Resumen
}

Los antibióticos equilibradores de la microbiota se han utilizado en la alimentación animal desde la década de 1950, al promover beneficios para la salud de los animales, sin embargo, el uso prolongado de estos aditivos desencadenó el problema de la resistencia bacteriana, lo que llevó a los organismos mundiales y nacionales (OMS, UE, FDA y MAPA) a prohibir varios aditivos. Sin embargo, las aves de corral en los sistemas industriales están sometidas a entornos densos y desafiantes, lo que hace imposible eximir a la dieta de compuestos que modulen la microbiota intestinal y, en consecuencia, favorezcan beneficiosamente la digestibilidad y la absorción de los nutrientes de la dieta. En este aspecto, el uso de aditivos equilibradores de la microbiota alternativos a los antibióticos, como los prebióticos, los probióticos y los simbióticos, se hace indispensable, porque son naturales, no causan resistencia bacteriana y promueven beneficios mutuos para la salud animal. Así, esta revisión pretende dilucidar los beneficios de los aditivos equilibrantes de la microbiota en la alimentación de las aves ponedoras comerciales, haciendo hincapié en los efectos producidos a partir de la modulación de la microbiota residente. La metodología adoptada fue un estudio descriptivo, que dio lugar a una revisión bibliográfica basada en artículos científicos de todo el mundo.

Palabras clave: Prebiótico; Probiótico; Resistencia bacteriana; Simbiótico.

\section{Introdução}

Os antibióticos têm sido utilizados na nutrição de poedeiras por décadas, com objetivo de melhorar o desempenho animal, proporcionando saúde do trato gastrointestinal e estimulando assim o máximo desempenho (promovendo uma maior absorção e integridade da mucosa intestinal), no entanto, pesquisas tem demonstrado que os antibióticos quando utilizados para tais fins, podem gerar bactérias resistentes tanto para os próprios animais, quanto para o ser humano quando em contato com produtos provindos da produção animal.

Nesse aspecto, organizações mundiais (WHO, 1997; UE, 2006 citado por Castanon 2007; FDA, 2018) e nacional (Brasil, 2020) ligadas à área da saúde, estão banindo cada vez mais o uso de antibióticos, quando utilizados para fins de promover o crescimento animal, o Brasil é um exemplo disso, pois baniu o uso de medicamentos à base de lincomicina, tiamulina e tilosina, pois os mesmos são classificados como importantes na medicina humana. Entretanto, as aves ainda continuam submetidas em ambientes desafiados, tornando impossível a isenção de compostos na dieta que modulem a microbiota intestinal (Toledo, et al., 2007), e consequentemente a digestibilidade e absorção dos nutrientes da ração (Matur, et al., 2010; Feitosa, et al., 2020). Nesse 
contexto, pesquisas estão sendo desenvolvidas com a finalidade de substituir os antibióticos por produtos naturais, que não desencadeie resistência bacteriana e nem resíduos nos produtos finais, dentre as alternativas se destacam os prebióticos, probióticos e simbióticos.

Os prebióticos, probióticos e simbióticos, oferecem mútuos efeitos sobre a saúde intestinal, bem como, melhorias no desempenho através da ação dos seus constituintes (Mohammed, et al., 2019). Os seus efeitos, modulam a microbiota indígena assim como as funções do trato gastrointestinal (TGI) por meio da redução do pH luminal, tornando um ambiente favorável à proliferação de cepas bacteriana benéfica, que estimularão a produção de bacteriocinas que ajudam a inibir o crescimento de bactérias patogênicas, e enzimas pancreáticas que potencializam o aproveitamento dos nutrientes provindos das dietas favorecendo um maior desempenho animal.

Esses benefícios provindos destes aditivos se caracterizam como alta relevância para a avicultura por beneficiarem o desenvolvimento dos animais, tanto nos aspectos evolutivos do TGI, microbiota vigente, desenvolvimento do tecido ósseo e do aparelho reprodutor. Esta revisão tem por objetivo elucidar os benefícios dos aditivos equilibradores de microbiota na alimentação de aves poedeiras comerciais, com ênfase nos efeitos produzidos a partir da modulação da microbiota residente.

\section{Revisão Bibliográfica}

\subsection{Aditivos equilibradores de microbiota intestinal}

Aditivos equilibradores da microbiota intestinal segundo a Instrução Normativa 13, de 30 de novembro de 2004 (alterada pela Instrução Normativa $n^{\circ}$ 44/15), são microrganismos que formam colônias ou outras substâncias definidas quimicamente que têm um efeito positivo sobre a microbiota do trato digestório (Brasil, 2015).

Os primeiros relatos do uso de aditivos equilibradores de microbiota foram em 1948 nos estudos de identificação e isolamento da vitamina $B_{12}$ em culturas fúngicas, no qual foi demonstrado que a massa micelar obtida nas culturas produziam antibióticos, que atuavam como melhorador de desempenho (Gonzales, et al., 2012). A descoberta dos antibióticos transformou o mundo ao tornar tratáveis doenças e permitir o uso em doses baixas para prevenir infecções.

Com tais pesquisas desenvolvidas o Food and Drug Administration (FDA) dos EUA em 1951 aprovou a utilização na alimentação animal, sem que fosse necessário a prescrição veterinária, visto que as doses usuais seriam subterapêuticas, apenas para fins de promover o benefício a microbiota e consequentemente ao desempenho animal (Gonzales, et al., 2012).

Desde então a avicultura industrial se promoveu com o uso constante de aditivos em dietas, por serem visíveis as melhorias no desempenho e na saúde do plantel. Entretanto, o uso constante e intenso dos antibióticos equilibradores de microbiota desencadeou a seleção de linhagens bacterianas resistentes.

A resistência microbiana aos antibióticos é um processo que ocorre naturalmente, porém o processo pode ser acelerado com a exposição ao uso excessivo de antibióticos. A resistência ocorre quando as cepas alvo se mutam e não respondem aos princípios ativos do medicamento que se tornam ineficazes (Cheng, et al., 2016).

Deste modo, a resistência bacteriana se tornou uma problemática na saúde animal e humana, por serem administrados em ambos medicamentos com mesmos princípios ativos. A contaminação de produtos de origem animal - carne, ovos, esterco - por resíduos dos antibióticos levaram aos órgãos mundiais (WHO, 1997; UE, 2006 - citado por Castanon, 2007) e nacional (Brasil, 2020) a elaborarem planos e normativas vetando a utilização de alguns antibióticos (Tabela 1) em dosagens subterapêuticas, pois o consumo destes produtos a longo prazo poderia levar a resistência bacteriana em humanos.

Apesar das proibições dos antibióticos pelos órgãos mundiais (WHO, UE, FDA) ligados à área de saúde, no Brasil segundo a normativa de número 01 de 13 de janeiro de 2020 imposta pelo órgão Ministério da Agricultura, Pecuária e Abastecimento - MAPA, o antibiótico bacitracina de zinco ainda é usual em dosagens subterapêuticas para a alimentação animal. 
Tabela 1. Antimicrobianos proibidos recentemente como melhoradores de desempenho e alguns aditivos equilibradores de microbiota intestinal aprovados no uso na alimentação animal.

\begin{tabular}{ll}
\hline & PROIBIDOS \\
\hline Nome & Instrução Normativa / Decreto / Lei \\
\hline Colistina & IN n $^{\circ}$ 45, de 22/11/2016 \\
Tilosina, Lincomicina e Tiamulina & IN n $^{\circ}$ 01, de 13/01/2020 \\
\hline \multicolumn{2}{c}{ APROVADOS } \\
\hline Nome & Classificação \\
\hline Bifidobacterium bifidum (ATCC 5860) & Probiótico \\
Bacillus licheniformis (ACCC 02002) & Probiótico \\
Enterococcus faecium (NIBH 15221) & Probiótico \\
Avilamicina & Melhorador de desempenho \\
Bacitracina de Zinco & Melhorador de desempenho \\
Extrato de casca de carvalho & Melhorador de desempenho \\
Extrato de Hemicelulose & Prebiótico \\
\hline
\end{tabular}

Fonte: Adaptado (MAPA, 2020).

\subsubsection{Bacitracina de zinco}

A bacitracina é um antibiótico polipeptídio não ribossomal produzido por cepas de Bacillus licheniformis e B. subtilis, cuja composição e estrutura são complexas e atuam sobre as bactérias Gram-positivas: estreptococos, estafilococos, corinebactérias e clostrídios (Pavli \& Kmetec, 2006; O’Donnell, et al., 2015). Existem três subgrupos de bacitracina: A, B e C. O subgrupo A é o principal constituinte das preparações comerciais (O’Donnell, et al., 2015).

A bacitracina contém um anel tiazolina e cadeias laterais de peptídeos. Após a administração, forma um complexo com C55-isoprenil pirofosfato, um componente da parede celular bacteriana. Esta molécula atua como um transportador envolvido na transferência de polissacarídeos, peptideoglicano e lipopolissacarídeos para a parede celular em crescimento. Portanto, a formação da parede celular bacteriana é atrofiada (O’Donnell, et al., 2015).

Recentemente Crisol-Martínez, et al. (2017), comprovou em sua pesquisa que a bacitracina ainda é eficaz sobre o desempenho e sobre a microbiota cecal de frangos de corte. Contudo, a tendência mundial é banir a utilização de antibióticos nas dietas dos animais.

Entretanto, os animais continuam submetidos a ambientes adensados que favorecem a proliferação de patógenos, doenças e estresse que deprimem o sistema imune, tornando os animais mais vulneráveis, sendo impossível a isenção de compostos na dieta que aprimorem a microbiota intestinal (Toledo, et al., 2007), e consequentemente a digestibilidade e absorção dos nutrientes da ração (Matur, et al., 2010; Feitosa, et al., 2020).

Por isso, há busca por aditivos equilibradores de microbiota alternativos e comensais, que não causem resistência bacteriana, tem sido constante. Pesquisas neste âmbito (Akbaryan, et al., 2019; Thema, et al. 2019) demonstraram que alternativas como prebióticos, probióticos e simbióticos tem sido promissora. 


\subsection{Prebiótico}

\subsubsection{Definição e fontes}

Os prebióticos são definidos como compostos não digeríveis que, por meio de sua metabolização por microrganismos no intestino, modulam a composição e / ou atividade da microbiota intestinal, conferindo efeito fisiológico benéfico ao hospedeiro (Bindels, et al., 2015). Sendo assim uma alternativa para aumentar o número de cepas benéficas no trato digestivo.

A composição dos prebióticos são essencialmente formadas por carboidratos com ramificações e tamanhos diferenciados, podendo ser monossacarídeos, dissacarídeos, oligossacarídeos e polissacarídeos (Raizel, et al., 2011). A sua extração pode vir de diversas fontes alimentares como alguns cereais, tubérculos e raízes, assim como da parede de microrganismos, tais como glucanos e mananos quando extraídos da parede celular da levedura Saccharomyces cerevisiae (Raizel, et al., 2011; Lemos, et al., 2016), mas em geral a maior parte da extração é de fonte vegetal. Dentre os prebióticos mais usuais estão os frutooligossacarídeos (FOS), mananoligossacarídeos (MOS) e os $\beta$-glucanos.

Os frutooligossacarídeos (FOS) e a inulina - sua versão de cadeia mais longa (de 3 à 60 monômeros), estão entre os prebióticos mais estudados em humanos e animais. Os FOS são carboidratos de cadeia curta e não digeríveis, formado por polímeros lineares naturais de 2 até 10 monoméricos, onde de 2 à 9 unidades de frutosil se ligam através de ligações glicosídicas $\beta$ - (2-1) e $\alpha$ - (1-2), terminadas por um resíduo de glicose (Pourabedin \& Zhao, 2015; Shang, et al., 2018; Macedo, et al., 2020) e obtidos através da hidrólise da inulina (Raizel, et al., 2011). Os FOS podem ser encontrados nas formas de 1-kestose (GF2), nistose (GF3) e frutofuranosil nistose (GF4) (Macedo, et al., 2020).

A ligação $\beta$-glicosídica presente nos frutanos confere resistência à quebra da molécula por parte das aves, pela ausência de enzimas digestivas específicas. Deste modo apenas grupos seletos de bactérias benéficas, como exemplo Bifidobacterium e Lactobacillus formadoras de ácido láctico, conseguem digerir este substrato e se beneficiar ocasionando aumento da população. Com o aumento da população destas cepas, consequentemente haverá maior produção de ácido lático, tornando o meio luminal levemente ácido deixando o ambiente inóspito para a proliferação de bactérias patogênicas, como Clostridium pefrigens e E. coli em aves (Ricke, 2015).

Outro grupo do prebiótico compreende os mananoligossacarídeos (MOS) que são oligômeros à base de manose ligados entre si por ligações glicosídicas $\beta$ - $(1,4)$, normalmente encontrados em determinadas plantas como o feijão ou na porção manoproteica da parede celular da Saccharomyces cerevisiae, cujos principais componentes, mananos e $\beta$-glucanas (manoproteínas), são conhecidos por induzir a ativação do sistema imunológico dos animais (Pourabedin \& Zhao, 2015; Diaz, et al., 2018).

Outro grupo compreende os $\beta$-glucanos que são polissacarídeos de cadeia longa, compostos de monômeros de D-glicose ligados entre si por ligações glicosídicas $\beta$ - $(1,3)$ e $\beta$ - $(1,6)$, derivados de leveduras ou de paredes celulares de fungos (Teng \& Kim, 2018). Por terem a composição formada por ligações beta, essa classe de prebiótico se ligam a receptores específicos de macrófagos que reconhecem os açúcares específicos encontrados em glicoproteínas da superfície epitelial, estimulando a fagocitose pelos macrófagos a produção de citocina, que ativam a produção de linfócitos aumentando consequentemente a resposta imune inata e adquirida (Świątkiewicz, et al., 2014).

As aves por não possuírem enzimas responsáveis pela hidrólise das ligações deste composto, acredita-se que este polissacarídeo alcance o trato gastrointestinal inferior sem ser digerido. Ao atingir a nível de intestino, os prebióticos contendo manose se ligam às lectinas patogênicas e impedem a fixação dos patógenos ao enterócito, deste modo há uma diminuição da população patogênica no trato por meio da eliminação (Pourabedin \& Zhao, 2015; Teng \& Kim, 2018). 


\subsubsection{Mecanismo de ação}

Em geral, os prebióticos quando inseridos as dietas das aves atuam de diferentes formas dentro dos segmentos do trato digestivo, obtendo maior atividade na parte inferior do trato (ceco) por haver maior população e diversidade microbiana. Os mecanismos de ação no organismo do animal variam de acordo com a fonte utilizada (MOS, FOS, $\beta$-glucanos, entre outros), sendo os mais relatados na literatura como substrato para cepas benéficas, barreira física no intestino e estimuladores do sistema imune.

Os prebióticos quando fornecidos como substratos para espécies microbianas benéficas, geram metabólitos, como, derivados de ácidos biliares, vitaminas e ácidos orgânicos - ácidos graxos de cadeia ramificada e ácidos graxos de cadeia curta (AGCC) - que são absorvidos pelo animal e algumas substâncias antibacterianas, como a bacteriocina que atua sobre cepas patogênicas, alterando a população da microbiota residente (Bindels, et al., 2015; Teng \& Kim, 2018).

Os ácidos orgânicos provindos da degradação dos prebióticos, alteram o pH intestinal deixando o lúmen levemente ácido tornando o meio inóspito para determinadas cepas patogênicas, como exemplos, dos gêneros Salmonella sp e E. coli (Lan, et al., 2017). Essa alteração de pH também estimula a produção de enzimas pancreáticas o que acarreta ao maior contato da ingesta com as enzimas melhorando a digestibilidade dos nutrientes (Ricke, et al., 2020).

Os metabólitos produzidos são aproveitados pelo animal de forma eficiente que acarreta na otimização no desempenho produtivo. Esses metabólitos gerados a partir da digestão dos substratos são aproveitados de forma mútua pelo animal, além de apresentar atividade antimicrobiana, melhora a integridade das células do enterócito e regula a população microbiana do trato gastrointestinal.

Como barreira física, os prebióticos possuem ligações glicosídicas que se aderem à mucosa intestinal formando uma espécie de barreira impedindo a adesão de bactérias, fungos e protozoários patogênicos à parede das células do enterócito, desta forma os patógenos se ligam ao prebiótico e são eliminados do trato digestivo através das fezes/excreta. Em resposta a ligação prebiótica-enterócito há um estímulo à produção de mucina pelas células caliciformes do epitélio luminal formando uma barreira natural de muco dificultando a aderência de patógenos (Forte, et al., 2018).

Essa adesão do prebiótico à mucosa também gera resposta imunológica, onde as células sentinelas como as dendríticas, macrófagos e os mastócitos ao realizarem o reconhecimento de padrões moleculares associados a patógenos capturam à molécula, processam e apresentam antígenos para os linfócitos (Antonialli, 2013; Teng \& Kim, 2018). Este reconhecimento induz a maturação da célula dendrítica, um processo essencial para ativar os linfócitos $\mathrm{T}$ e $\mathrm{B}$, maturados pelos órgãos Timo e Bursa de Fabrício nas aves, respectivamente (Antonialli, 2013).

Outra forma de atuação do prebióticos é como antígenos não patogênicos. Eles por serem reconhecidos pelos receptores de células imunes, agem também como adjuvantes de vacinas aumentando os títulos de anticorpos (Teng \& Kim, 2018). Desta forma os prebióticos apresentam vários efeitos benéficos fisiológicos, metabólicos e imunológicos, conferindo ao animal melhoria na microbiota residente, na integridade dos enterócitos e consequentemente no desempenho produtivo.

Diversas pesquisas vêm demonstrando os benefícios mútuos destes substratos na alimentação de aves, quando inseridos sós ou em conjunto com outros grupos prebióticos. No estudo realizado por Park, et al. (2017), foi constatado que frutooligosacarídeos, galacto-oligossacarídeos e fibra alimentar de ameixa enriqueceram a comunidade bacteriana e modulam a diversidade do microbioma. Essa modulação levou ao aumento de bactérias produtoras de ácidos graxos de cadeia curta, como o butirato, que tem potencial em reduzir infecção por Salmonella, inibir a inflamação e pode promover as taxas de renovação da mucosa celular.

Corigan, et al. (2015), ao identificar os efeitos reprodutíveis da suplementação dietética com um mananoligossacarídeo (MOS) na estrutura e função da comunidade bacteriana cecal de frangos de corte em um ambiente de produção comercial, constatou alteração na comunidade bacteriana de 7 dias de suplementação até 35 dias, onde os filos Bacteroidetes foi substituído 
pelo Firmicutes. Esse resultado indicou que as alterações das comunidades bacterianas como resultado de MOS podem alterar a capacidade funcional do ceco.

O estudo com adição de $\beta-1,3$-glucano nas concentrações de 0,1 e $0,2 \%$ às rações de frangos de corte realizado por Zhang, et al. (2020), constatou que as aves ao consumirem a dieta enriquecida do aditivo, houve aumento na digestibilidade da energia, reduziu a população de E. coli no íleo e consequentemente melhorou a qualidade da carcaça.

Apesar de cada grupo prebiótico agir de forma semelhante, às particularidades entre os grupos são existentes, isso é o que nos mostram as pesquisas, contudo é um aditivo alternativo à problemática da resistência bacteriana causada pela administração contínua de antibióticos e que deve ser melhor estudado afim de esclarecer suas particularidades.

\subsection{Probiótico}

\subsubsection{Definição}

O termo probiótico ganhou várias definições ao longo dos anos, sua primeira descrição foi realizada em 1965 por Lilly e Stillwell, seguida de Parker (1974) e Fuller (1989), contudo a definição mais amplamente aceita sobre os probióticos, é descrita pelos órgãos de pesquisa conjunta FAO e WHO, sendo "microrganismos vivos que, quando administrados em quantidades adequadas, conferem um benefício à saúde do hospedeiro" (FAO, 2016).

Nos últimos anos, pesquisadores concentraram seus estudos no fornecimento de novos suplementos alimentares que previnem doenças, estimulem o aumento da imunidade das aves e diminuam os riscos biológicos causados pelo uso dos antibióticos. Os probióticos se mostram possíveis substitutos aos antibióticos, pelo seu histórico de uso seguro em produtos lácteos fermentados e pelos seus efeitos benéficos, altamente reconhecidos na saúde humana.

Os probióticos são constituídos por várias espécies de bactérias benéficas, fungos ou leveduras que além de promover o crescimento animal também são capazes de eliminar bactérias patogênicas como Salmonella typhimurium, Staphylococcus aureus, Escherichia coli e Clostridium perfringens (Iannitti \& Palmieri, 2010; Alagawany, et al., 2018). Podem ser fornecidos como um suplemento alimentar microbiano vivo na dieta ou na água das aves, também podem ser administrados ao embrião em desenvolvimento usando tecnologia de alimentação in ovo (Pender, et al., 2016; Jha, et al., 2020).

\subsubsection{Mecanismo de ação e fontes}

Dentre os mecanismos de ação dos probióticos destaca-se a inibição de patógenos pela produção substâncias antibacterianas, como as bacteriocinas, ácidos orgânicos, peróxido de hidrogênio e defensinas, inibição competitiva pelo bloqueio de adesão das bactérias patogênicas aos locais de ligação epitelial intestinal, modulação das respostas imune do hospedeiro, regeneração da mucosa intestinal, secreção de enzimas digestivas (Tiwari, et al., 2012; Alagawany, et al., 2018).

Os probióticos também podem atuar na regulação de produção de citocinas anti e pró inflamatórias (Roselli, et al., 2005; Alagawany, et al., 2018) podem estimular a produção de anticorpos, aumentar a atividade das células naturais de killer e macrófagos, também podem estimular as funções de barreira epitelial e regular a produção de muco, motililade intestinal, bem como, podem estimular o baixo $\mathrm{pH}$, que facilita a absorção de proteínas e minerais como cobre, cálcio, ferro, manganês e magnésio (Raghuwanshi, et al., 2015; Alagawany, et al., 2018).

Cada probiótico possui mecanismos de ação distintos, o que lhes confere uma eficácia protetora variável. Nesse contexto, muitos produtos comerciais utilizam um mix de cepas probióticas, que agem em diferentes locais e modos, criando efeitos sinérgicos benéficos ao animal.

Para que se utilize uma bactéria como probiótico, deve-se seguir alguns critérios básicos, como tolerância a condições gastrointestinais, capacidade em suportar pH baixo e altas concentrações de ácidos biliares (FAO, 2016), exclusão competitiva de patógenos e capacidade de aderir à mucosa gastrointestinal (Klaenhammer \& Kullen, 1999; Gadde, et al., 2017; Jha, et al., 
2020). Além disso, os probióticos são selecionados com base em sua sobrevivência na fabricação, armazenamento, transporte, processos de aplicação, capacidade de manter a viabilidade e suas características desejáveis (FAO, 2016; Jha, et al., 2020).

Existe vários tipos de microrganismos com potencial para serem utilizados como fonte probiótica, contudo, os tipos mais comuns são as bactérias ácido lácticas e as bifidobactérias, embora outras bactérias e certas leveduras também sejam utilizadas (Didari, et al., 2014). As cepas benéficas de caráter probiótico mais comumente usadas na nutrição animal são as do gênero Lactobacillus spp, Bifidobacterium spp, Enterococcus spp, Bacillus subtilis e Saccharomyces spp. Podendo estas serem extraídas de produtos fermentados, não fermentados e do corpo animal/ humano (leite, conteúdo intestinal, fezes) (Soccol, et al., 2010; Alagawany, et al., 2018).

\subsubsection{Lactobacillus acidophilus}

As bactérias do gênero Lactobacillus pertencem ao filo Firmicutes, classe Bacilli, ordem Lactobacillales, família Lactobacillaceae (Schmitt, 2014). São bactérias Gram-positivas, não formadoras de esporos e facultativamente anaeróbias ou micro- aerofílicas em formato de bastonetes, constituem um dos gêneros de bactérias produtoras de ácido láctico - LABs (Goldstein, et al., 2015). O gênero é compreendido por 261 espécies (Zheng, et al., 2020) sendo estas encontradas em diferentes ambientes, como plantas, solos, vegetais, cereais, frutas, bebidas fermentadas, queijos, pele, cavidade oral, trato gastrointestinal de animais e humanos, dentre outros (Mesquita, et al., 2017). São bactérias bastantes fastidiosos, por isso precisam de um meio rico em nutrientes, contendo aminoácidos, peptídeos, carboidratos, ácidos graxos, sais, derivados de ácidos nucleicos e vitaminas para se desenvolverem (Carr, et al., 2002; Schmitt, 2014).

Os lactobacilos podem ser divididos em 2 grupos metabólicos: homofermentativo, convertem a glicose em ácido lático, e heterofermentativo, convertem a glicose em ácido lático, ácido acético, etanol e $\mathrm{CO}_{2}$. Esses metabólitos podem reduzir o pH do lúmen intestinal, tornando o ambiente desfavorável para as bactérias patogênicas (Menconi, et al., 2011). Pesquisas constatam que cepas de lactobacillus exercem efeito de exclusão competitiva em enterobactérias, como Salmonella enterica sorovar Enteritidis em galinhas (Penha Filho, et al., 2015). Além disso, influenciam positivamente o equilíbrio da microbiota gastrointestinal, aumentando a presença de bactérias benéficas, como Bifidobacterium spp., e reduzindo bactérias potencialmente prejudiciais, como Clostridia, Estafilococos e Escherichia coli (Forte, et al., 2016 ).

Os Lactobacillus acidophilus é uma das espécies considerada mais importantes dentro do gênero Lactobacillus, são bastonetes Gram-positivos, não formadores de esporos, com extremidades arredondadas, que ocorrem isoladamente, em pares e em cadeias curtas, geralmente com dimensões de 0,6-0,9 × 1,5-6 $\mu \mathrm{m}$ (Ozogul \& Hamed, 2016). São encontrados principalmente nos intestinos de animais e humanos (Schmitt, 2014) e na vagina de ambos, onde o ambiente pode ser bastante ácido (Ozogul \& Hamed, 2016). Costumam ser utilizados como probióticos devido sua resistência à bile e seu alto potencial em estabelecer um equilíbrio saudável entre a microbiota benéfica e patogênica.

Os Lactobacillus acidophillus possuem mecanismos de ação semelhante à de outras espécies de lactobacillus, onde vão atuar aderindo-se ao epitélio intestinal, formando uma barreira que previne a colonização de microrganismos indesejáveis devido à competição por nutrientes e sítios de aderência, além disso, podem atuar liberando fatores antimicrobianos como bacteriocinas, ácidos graxos de cadeia curta, peróxido de hidrogênio, diacetil e amônia (Ozogul \& Hamed, 2016).

As bacteriocinas produzidas pelos L. acidophillus são as do tipo lactacina - B (Tabasco, et al., 2009; Hegarty, et al., 2017; Dean, et al., 2020), vão atuar destruindo as células-alvo das bactérias patogênicas pela formação de poros e pela inibição da síntese da parede celular. Já os ácidos graxos de cadeia curta, como de exemplo ácido láctico e ácido acético, produzidos no processo de fermentação, reduzem o pH do lúmen intestinal, condicionando à eliminação das bactérias patogênicas gramnegativas, pelo rompimento das membranas externas. 
Pesquisas cientificas tem demonstrado os benefícios proporcionados pelos Lactobacillus acidophilus. Li, et al. (2018), avaliando os efeitos de Lactobacillus acidophilus sobre o desempenho de crescimento e saúde intestinal de frangos de corte desafiados por Clostridium perfringens, observaram que a cepa probiótica pode modular a microbiota intestinal, aliviar as inflamações e o comprometimento do intestino, bem como reduzir os índices de mortalidade de frangos desafiados com $C$. perfringens.

Atabaigi Elmi, et al. (2020), avaliando os efeitos de Lactobacillus acidophilus e antibacterianos naturais no desempenho de crescimento e colonização de Salmonella em frangos de corte desafiados com Salmonella enterica, concluíram que os lactobacilos melhoram as características de desempenho de crescimento, morfologia intestinal, inibição do crescimento de Salmonella, podendo ser utilizados como uma alternativa adequada a muitos antibióticos.

\subsubsection{Bifidobacterium bifidum}

As bactérias do gênero Bifidubacterium pertencem ao filo Actinobactéria, ordem Bifidobacteriales e familia Bifidobacteriaceae (Lee \& O'Sullivan, 2010). Assim como as bactérias do gênero Lactobacillus, também pertencem ao grupo das bactérias ácido lácticas - LABs (Salminen, et al., 1998; Picard, et al., 2005). São bactérias gram-positivas, anaeróbios estritos, imóveis, não formadores de esporos, curtos e irregulares, possuem formato de bastonete curvo com bifurcação em formato de $\mathrm{V}$ ou Y com ramificações rudimentares (Butta, et al., 2017).

O gênero Bifidobacterium é compreendido por 48 espécies e subespécies (Bunesova, et al., 2014), sendo estas encontradas em ambientes como intestinos de animais, humanos e insetos, bem como no leite cru e na cárie dentaria humana (Lee \& O'Sullivan, 2010). Em aves podem ser encontradas tanto no intestino delgado, quanto no grosso (Figueira, 2013). Podem fermentar oligossacarídeos não digeríveis no ceco e utilizá-los como fonte de carbono e energia (Gomes \& Malcata, 1999; Figueira, 2013).

Dentre as características benéficas relacionados aos Bifidobacterium pode-se destacar a inibição do crescimento de bactérias patogênicas devido a produção de ácidos graxos de cadeia curta como acetato e lactato (Abd El-Hack, et al., 2020), bacteriocinas e pela redução de pH intestinal, auxílio sobre a digestão e absorção de nutrientes, estímulo sobre a síntese de vitaminas do complexo B e imunidade devido a ativação da proliferação dos macrófagos (Leahy, et al., 2005; Figueira, 2013) e também auxiliam na síntese da produção de mucina que é uma glicoproteína ligada à proteção da mucosa intestinal.

Os Bifidobacterium produzem dois tipos de bacteriocinas, a bifidina e bifidocina B. A bifidocina B vai atuar como agente antibacteriano em algumas cepas patogênicas de origem alimentar, como Lactobacillus, Leuconostoc, Listeria, Bacillus, Enterococcus e Pediococcus spp. Enquanto a bifidina só é ativa contra Micrococcus flavus e Staphylococcus aureus (Shah \& Dave, 2002; Abdel-Moneim, et al., 2019).

Apesar das bifidobactérias serem consideradas como anaeróbios estritas, existem algumas cepas que podem sobreviver na presença de $\mathrm{O}_{2}$, como as cepas de Bifidobacterium boum, Bifidobacterium thermophilum e Bifidobacterium animalis spp. (Bunesova, et al., 2014).

As cepas de Bifidobacterium bifidum se destacam dentro do gênero dos Bifidobacterium devido aos seus benefícios, os quais são modulação da microbiota intestinal, imunoestimulação, competição com bactérias patogênicas por locais de fixação intestinal e nutrientes, produção de substâncias antimicrobianas como ácido láctico e acético que podem inibir tanto bactérias Gram-positivas ou negativas (El-Moneim, et al., 2019).

Estrada, et al. (2001), avaliando os efeitos de uma cepa de Bifidobacterium bifidum sobre os níveis de populações bacterianas fecais, incidência de celulite aviária e desempenho de crescimento em frangos de corte, constataram efeitos significativos sobre o desempenho de crescimento, reduções dos números de bactérias patogênicas como coliformes e clostrídios, bem como, reduções dos números de animais com celulite aviária. 
Em pesquisa El-Moneim, et al. (2019), avaliando a administração in ovo de duas cepas probióticas Bifidobacterium

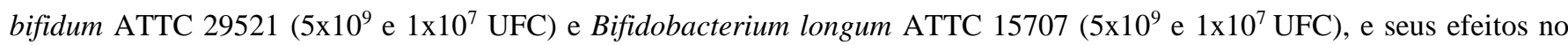
desempenho e na expressão gênica em pintos de corte, constataram melhorias significativas no peso corporal vivo, ganho de peso corporal, taxa de conversão alimentar, parâmetros hematológicos e altura das vilosidades sem efeito negativo sobre as características de carcaça e parâmetros de indicação da função hepática e renal.

\subsubsection{Bacillus subtilis}

O gênero Bacillus é composto por bactérias gram-positivas em forma de bastonete, pertencentes ao filo Firmicutes, ordem Bacillales, família Bacillaceae. São bactérias formadoras de esporos, aeróbia ou anaeróbia facultativa. Em geral, o gênero Bacillus é designado como um grupo habitante no solo, contudo, podem ser extraídos de outras fontes como ar, água, vegetais, alimentos, e intestino animal e humano (Elshaghabee, et al., 2017).

Os Bacillus são bactérias que se desenvolvem em ambientes com temperaturas em torno de 25 a $37{ }^{\circ} \mathrm{C}$, apesar de existir algumas cepas que podem crescer em faixa de temperatura muito altas ou muito baixas. Algumas cepas também podem habitar ambientes com $\mathrm{pH}$ ao extremo, podendo crescer em pH entre 2 e 10, sendo essas heterogeneidades de ambientes e condições de crescimento, reflexos da variedade de ambientes que a espécie pode habitar e a quantidade de substrato que podem utilizar em prol do seu crescimento (Santos, 2018).

Em condições ambientais estressantes os Bacillus podem produzir esporos que permanecem em um estado dormente por longos períodos de tempo, vantagem que os distinta sobre os Lactobacillus e Bifidobacterium. Os esporos dos bacilos podem resistir temperaturas de até $113^{\circ} \mathrm{C}$ por um período de até 8 minutos, além disso, podem resistir a pH baixos, bem como sais biliares e outras condições adversas do trato gastrointestinal (Barbosa, et al., 2005; Grant, et al., 2018).

Os esporos dos bacilos desempenham saúde intestinal não apenas por mecanismos de exclusão competitiva, mais também pela produção de peptídeos antimicrobianos (PAM), que são citotóxicos para as bactérias patogênicas, o que reduz os sinais associados as doenças infecciosas entéricas, como a coccidiose aviária (Grant, et al., 2018).

Os bacilos são produtores reconhecidos de peptídeos antimicrobianos a mais de 50 anos, produzem cerca de 66 tipos diferentes de PAM, sendo que alguns já foram purificados e comercializados pela indústria. Algumas bactérias produzem os PAM de forma ribossômica, onde os mesmos vão atuar em uma faixa antimicrobiana mais estreita contra microrganismos intimamente relacionados, enquanto outras bactérias que produzem de forma não-ribossômica, onde moléculas precursoras codificadas por genes são montadas pós-tradução por enzimas, exercem uma atuação em faixa antimicrobiana mais ampla (Sumi, et al., 2015; Grant, et al., 2018).

As bacteriocinas são os principais PAM produzidos de forma ribossômica, se enquadram em três classes principais (Zhao \& Kuipers, 2016 ). Classe I são os lantibióticos que contêm os aminoácidos modificados lantionina e metillantionina, classe II são bacteriocinas não modificadas de baixo peso molecular (<30 kDa) e classe III são proteínas que possuem alto peso molecular e que não toleram o calor (> $30 \mathrm{kDa}$ ) (Grant et al., 2018).

As bacteriocinas atuam de maneira a formar poros na parede celular das bactérias, inicialmente por atração pelas cardiolipinas carregadas negativamente, fosfatidilserina ou fosfatidilglicerol. Após a ligação a receptores específicos da parede celular, o espectro da atividade antimicrobiana é dependente do peptídeo (Lee \& Kim, 2011; Grant, et al., 2018).

Os bacilos também produzem PAM de forma não ribossômica por meio de mecanismos detalhados de montagem contendo mais de 300 precursores diferentes, que são mediados por peptídeos sintases. Esses PAM possuem uma ampla gama de inibições microbianas e são eficazes contra bactérias Gram-negativas e positivas, bem como a fungos, leveduras e até mesmo a vírus (Hancock \& Chapple, 1999; Grant, et al., 2018). 
Os PAM não ribossomal produzidos pelos bacilos mais bem estudados são as bacitracinas e gramicidinas, devido seus usos como antimicrobianos na área médica. Outros PAM não ribossomais produzidos pelos bacilos são iturinas e fengicinas, que são lipopeptídeos com atividade antifúngica (Maget-Dana \& Peypoux, 1994; Deleu, et al., 2008).

Os Bacillus subtilis é considerado uma das espécies que mais se destacam dentro do gênero bacillus, devido ao fato dos mesmos possuírem características biológicas únicas, tais como crescimento rápido, formação de esporos em ambientes adversos, resistência a ácidos, alcalinos e calor. Devido ao seu crescimento rápido os esporos dos Bacillus subitilis possuem a capacidade de alojar-se no trato intestinal para crescimento e reprodução, após os processos de extrusão e granulação no processamentos das rações, e após exposição a ambiente contendo ácido forte no intestino animal (Gao, et al., 2017).

Além dessas características, os B. subtilis por ser bactérias aeróbias podem consumir oxigênios livres enquanto passam pelos processos de reprodução no trato intestinal, devido a esse mecanismo, os bacilos podem controlar o crescimento de algumas bactérias patogênicas aeróbicas e aumentar o crescimento de bactérias benéficas anaeróbicas, como os Lactobacillus, Bifidobacterium e leveduras (Gao, et al., 2017). Os B. subtilis possuem capacidade de manter e restaurar o equilíbrio da microbiota intestinal, promover o crescimento animal, bem como melhorar as funções imunológicas e manter a resistência dos animais perante as doenças (Tannock, et al., 2000; Gao, et al., 2017).

Vários são os estudos que demonstram o potencial dos bacilos como fonte probiótica. Bilal, et al. (2020), avaliando os efeitos de duas cepas de Bacillus (pumilus e subtilis) sobre o desempenho de crescimento, microbiota intestinal, imunidade e saúde intestinal, observaram que a suplementação com as duas cepas probiótica conferiu benefícios a saúde intestinal para os frangos de corte, promovendo a integridade e função intestinal juntamente com a ativação de TREG do sistema imunológico.

Zhang, et al. (2021), avaliando os efeitos do B. subtilis no desempenho de crescimento, morfologia intestinal e composição microbiana cecal de frangos de corte, observaram melhora no desempenho de crescimento das aves, composição da microbiota intestinal e manutenção da saúde intestinal das aves.

\subsubsection{Saccharomyces cerevisiae}

As Saccharomyces cerevisiae é um organismo eucariótico, unicelular, pertencente ao reino Fungi, da classe Hemiascomycetes, ordem Endomycetales, família Saccharomcetaceae, sub-família Saccharomycetoideae e gênero Saccharomyces. A Saccharomyces é um tipo de levedura considerada benéfica, devido aos seus extratos serem ricos em proteínas, vitaminas (B6, tiamina, biotina, riboflavina, ácido nicotínico e pantotênico), minerais (magnésio e zinco) e nucleotídeos (Figueira, 2013; Elghandour, et al., 2019).

Este gênero é bastante utilizado na indústria de vinhos e alimentos para a fermentação natural dos produtos, mas recentemente tem sido estudada como fonte probiótica para humanos e animais de produção, devido a sua capacidade de impedir a instalação de cepas patogênicas (E. coli, S. Typhi e S. Typhimurium) no trato digestivo, através da adesão aos patógenos, neutralizando inclusive a translocação da Salmonella do trato digestivo para o fígado, baço e linfonodos mesentéricos, mantendo assim a integridade do epitélio intestinal e dos demais órgãos (Silva, 2012; Palma, et al., 2015).

Uma das características que tornaram as Saccharomyces cerevisiae como uma alternativa probiótica, foi o fato desta cepa resistir ao pH 2,0, bem como, sais biliares, digestão in vitro e por possuir capacidade de formar agregados celulares de superfície hidrofóbica, ou seja, apresenta alta capacidade de formar colônias e de se aderir ao epitélio intestinal, além de não apresentarem atividade hemolítica e serem sensíveis à nistatina, trazendo uma maior seguridade de seu uso (Romero-Luna, et al., 2018; Puppala, et al., 2018).

Quando adicionado a dieta das aves, as Saccharomyces cerevisiae, potencializa o desempenho produtivo por melhorar a eficiência alimentar, condicionar a uma melhor digestibilidade do alimento, reduzir o número de bactérias patogênicas, melhorar a saúde animal e reduzir os impactos ambientais negativos da produção animal (Elghandour, et al., 2019). 
Bovo, et al. (2015), em seu estudo verificou que a Saccharomyces $(0,1 \mathrm{~g} / \mathrm{kg}$ de ração) possui a capacidade de adsorver micotoxinas como a aflatoxinas em testes in vitro, e que quando estas células são adicionadas em dietas para frangos de corte tem a capacidade de reduzir a gravidade das alterações histológicas no fígado e rins causados pela afltoxina B1.

Estas cepas também são capazes de ativar o sistema imunológico a ponto de haver melhorias do estado imunológico em resposta ao desafio microbiano. Morales-Lopez e Brufau (2013), constataram este efeito em sua pesquisa ao adicionarem a Saccharomyces Cerevisiae ( $0,5 \mathrm{~g} / \mathrm{kg}$ de ração) a dietas para frangos de corte desafiados com E. coli, observando que órgãos imunológicos como a Bursa de Fabricius aumentou de tamanho nas aves que consumiam o probiótico, devido a interação probiótico-sistema imunológico, apesar do desafio.

\subsubsection{Enterococcus faecium}

Os enterococos foram citados pela primeira vez em 1899, onde pesquisadores ao descreverem bactérias comensais que possuíam capacidade de se tornar patogênica descobriram este gênero (Fiore, et al., 2019; García-Solache \& Rice, 2019). A partir de então, pesquisas se difundiram com finalidade de descreverem o novo gênero, pois foi observado que suas cepas tinham potencial para causar infecções em animais e humanos.

Os enterococos são bactérias gram-positivas ovóides não formadoras de esporos que existem individualmente ou em pares, e habitam o intestino de animais vertebrados e invertebrados. Este gênero pertence ao filo Firmicutes da classe Bacili, ordem Lactobacillales e família Enterococcaceae, (Fiore, et al., 2019; García-Solache \& Rice, 2019). Estas bactérias são anaeróbias quimio-organotróficas facultativas com metabolismo homofermentativo e pertencentes ao grupo de bactérias ácido láticas (LAB's), assim como os Bifidobacterium spp. e Lactobacillus spp. Este gênero compreende mais de 50 cepas e podem ser isoladas do solo, da superfície da água do mar e em associações com plantas e produtos alimentícios fermentados (Fiore, et al., 2019; García-Solache, 2019).

Este gênero possui uma capacidade ampla de colonizar o trato digestivo, assim como, multiplicar-se, pois apresentam características de permanecerem vivas em faixa de temperatura e pH de grande amplitude, conseguem sobreviver à dessecação e crescer na presença de 6,5\% de $\mathrm{NaCl}$ e $40 \%$ de sais biliares (Lebreton, et al., 2014).

Algumas das cepas pertencentes ao gênero são ligadas a infecções sistêmicas associadas à saúde (Hanchi, et al., 2018; Fiore, et al., 2019; García-Solache \& Rice, 2019), entretanto pesquisas (Mannu, et al., 2003) demonstraram que cepas enterocócicas sem atividade hemolítica e não portadora de genes resistentes à citolisina e vancomicina podem ser consideradas seguras e utilizadas como probiótico (Khan, et al., 2010).

Os enterococos despertaram o interesse probiótico por apresentarem características de resistência a sucos gástricos e por sua capacidade de produzir uma variedade específica de bacteriocina, a enterocina, que age sobre as bactérias gram-positivas (Hanchi, et al., 2018) em particular, sobre o gênero Listeria (Khan, et al., 2010 ). Os E. faecium e E. faecalis são os maiores produtores dessas bacteriocinas, por isso os estudos estão mais voltados para o potencial probiótico destas cepas (Hanchi, et al., 2018).

A suplementação de cepas enterocócicas, como E. faecium por exemplo, podem melhorar o desempenho produtivo das aves através da modulação da microbiota residente, através da diminuição do $\mathrm{pH}$ luminal e produção de bacteriocinas, tornando o meio inóspito para a proliferação de cepas patogênicas (E. coli, Salmonella spp.), e favorável as cepas benéficas, como Lactobacillus spp. que se desenvolvem em meio levemente ácido (Khan, et al., 2010).

A suplementação do probiótico E. faecium $\left(6 \times 10^{8} \mathrm{UFC} / \mathrm{kg}\right)$ pode levar ao aumento nos filos Bacteroidetes e Firmicutes, na classe Bacteroidia e Clostridia, na ordem Bacteroidales e clostridiales, e na família Lachnospiraceae, além de promover enriquecimento no filo Proteobacteria e na classe Gammaproteobacteria, constata a pesquisa de Wang, et al. (2021), com aves matrizes. 
Essa modulação microbiana influencia em toda fisiologia e metabolismo da ave, pois estimula potencialmente a atividade das enzimas digestivas, melhorando a absorção e digestão de nutrientes, assim como, promove redução de amônia e sulfeto de hidrogênio por haver maior aproveitamento do nitrogênio, aumento de órgãos linfóides como a Bursa de Fabricius (Lan, et al., 2017), aumento do desempenho produtivo, elevação de níveis séricos do hormônio folículo-estimulante (FSH) (Wang, et al., 2021), aumento no peso do baço, maior comprimento de órgãos intestinais como jejuno, íleo e ceco (Castañeda, et al, 2021).

\subsection{Simbiótico}

O termo simbiótico foi formado a partir do prefixo grego "syn”, que significa “junto", e do sufixo "biótico", que significa “pertencente à vida" (Swanson, et al., 2020), foi descrito pela primeira vez em 1995 por Gibson \& Roberfroid, definido como "uma mistura de probióticos e prebióticos que afeta beneficamente o hospedeiro, melhorando a sobrevivência e implantação de suplementos alimentares microbianos vivos no trato GI, estimulando seletivamente o crescimento e / ou ativação do metabolismo de uma ou de um número limitado de bactérias promotoras da saúde, melhorando assim o bem-estar do hospedeiro" (Gibson \& Roberfroid, 1995).

Posteriormente estudos sugeriram novos conceitos sobre o termo "Simbiótico". Silva e Filho, (2000), destaca que dentro da classe de alimentos funcionais os aditivos simbióticos vêm a ser uma mistura de probióticos e prebióticos em um só produto, trazendo além de componentes da microbiota intestinal, também substâncias que estimulem o desenvolvimento e a atividade desta mesma microbiota privilegiando além do bem-estar do hospedeiro, também o seu desenvolvimento.

Alloui, et al. (2013), conceituaram os simbióticos como sendo suplementos nutricionais que combinam probióticos e prebióticos de forma sinérgica. Segundo os mesmos autores uma das principais razões para o uso de um simbiótico é a concepção de que um probiótico, sem seu substrato prebiótico, não sobrevive bem no sistema digestivo.

Em 2017 o Compêndio Brasileiro de Alimentação Animal definiu o simbiótico como "misturas de probióticos e prebióticos que afetam beneficamente o hospedeiro melhorando a sobrevivência e implantando suplementos vivos no trato gastrointestinal” (Reis \& Vieites, 2019).

Atualmente o termo "Simbiótico” foi redefinido pela Associação Científica Internacional para Probióticos e Prebióticos (ISAPP), como sendo "uma mistura que compreende microrganismos vivos e substratos utilizados seletivamente por microrganismos hospedeiros benéficos que confere um benefício à saúde do hospedeiro" (Swanson, et al., 2020). Ainda segundo o órgão ISAPP existem duas categorias de simbióticos reconhecidas, os complementares e os sinérgicos.

Um simbiótico complementar é composto por um probiótico e um prebiótico (mais de um componente pode ser utilizado), trabalham de forma independente para alcançar um ou mais benefícios à saúde do hospedeiro, não requerendo funções co-dependentes, seus componentes devem ser administrados em doses que se mostrem eficazes apenas para os componentes. Já o simbiótico sinérgico é composto por microrganismos vivos e substratos, sendo projetados para trabalharem em conjunto (não independentemente) ou seja, os substratos sendo utilizados seletivamente pelos microrganismos vivos administrados, trazendo saúde aos hospedeiros (Swanson, et al., 2020).

Dentre os tipos de simbióticos existentes, o que mais se utiliza em ensaios laboratoriais ligado à área de ciência animal é o sinérgico, devido a ação conjunta de seus constituintes (probióticos e prebióticos) em benefício à saúde do hospedeiro. Um dos possíveis motivos em explorar o efeito sinérgico em um simbiótico, seria o fato em superar algumas dificuldades encontradas quando ministrados apenas um componente. Nesse aspecto, a combinação adequada de ambos os componentes em um único produto deve garantir um efeito superior, em comparação com a atividade do probiótico ou prebiótico sozinho (Bengmark, 2005; Markowiak \& Slizewska, 2018). 
De modo geral o mecanismo de ação do simbiótico sobre a saúde animal está ligado ao fato de seus componentes favorecerem o equilíbrio sobre a microbiota intestinal através da redução do pH luminal, tornando o meio propício ao crescimento de cepas bacterianas benéficas que estimularão a produção de bacteriocinas que ajudam a inibir o crescimento de bactérias patogênicas (Alavi, et al., 2012) e enzimas pancreáticas para otimizar o aproveitamento dos nutrientes provindos da dieta favorecendo o desempenho animal (Kuritza, et al., 2014; Al-Khalaifah, 2018; Forte, et al., 2018).

Considerando um grande número de combinações possíveis de probióticos e prebióticos, a aplicação de simbióticos para modulação da microbiota intestinal em animais parece promissora. Várias são os estudos demonstrando os efeitos positivos dos simbióticos na alimentação animal.

Luoma, et al. (2017) analisando os efeitos inibitórios de um produto simbiótico (1,0 g/kg) à base de Lactobacillus reuteri, Enterococcus faecium, Bifidobacterium animalis, Pediococcus acidilactici e frutooligossacarídeo nos parâmetros de produção, no perfil da microflora intestinal e nos parâmetros imunológicos em galinhas poedeiras White Leghorn com e sem desafio de Salmonella, observaram que, os animais submetidos aos tratamentos contendo o aditivo simbiótico tiveram maior produção de ovos, menor infecções por Salmonella, fato justificado pelas maiores concentrações de imunoglobulinas do tipo A $(\operatorname{Ig} \mathrm{A})$, caracterizando maior proteção para as aves.

Abdel-Wareth, et al. (2019), avaliando os efeitos de um aditivo simbiótico a base de Enterococuus faecium, Lactobacillus reuteri, Pediococcus acidilactici, Bifidobacterium animalis (probióticos) e Frutooligossacarídeo (prebiótico), na dieta de frangos de corte em condições climáticas quente, observaram efeitos positivos sobre o desempenho produtivo, qualidade da carne, redução dos níveis de amônia das excretas, bem como a redução dos níveis de bactérias patogênicas no animal.

\section{Considerações Finais}

A bacitracina de zinco ainda é usual no Brasil, contudo a política exterior tem pressionado o país a proibir o uso deste antibiótico e entre outros ainda usuais. Contudo, o adensamento de animais promovido pelo sistema de criação industrial torna impossível a isenção de compostos na dieta que favoreçam a microbiota residente e consequentemente o desempenho zootécnico, desta forma, os aditivos equilibradores de microbiota como os prebióticos, probióticos e simbióticos são importantes, por estes apresentarem alto potencial como substituto aos antibióticos, como demonstraram as pesquisas abordadas nesta revisão.

\section{Referências}

Abd El-Hack, M. E., El-Saadony, M. T., Shafi, M. E., Qattan, S. Y. A., Batiha, G. E., Khafaga, A. F., Abdel-Moneim, A. E., \& Alagawany, M. (2020). Probiotics in poultry feed: A comprehensive review. Journal of Animal Physiology and Animal Nutrition, 104(6), 1835-1850. https://doi.org/10.1111/jpn.13454

Abdel-Moneim, A. M. E., Elbaz, A. M., Khidr, R. E. S., \& Badri, F. B. (2019). Effect of in Ovo Inoculation of Bifidobacterium spp. on Growth Performance, Thyroid Activity, Ileum Histomorphometry, and Microbial Enumeration of Broilers. Probiotics and Antimicrobial Proteins, 12(3), 873-882. https://doi.org/10.1007/s12602-019-09613-x

Abdel-Wareth, A. A. A., Hammad, S., Khalaphallah, R., Salem, W. M., \& Lohakare, J. (2019). Synbiotic as eco-friendly feed additive in diets of chickens under hot climatic conditions. Poultry Science, 98(10), 4575-4583. https://doi.org/10.3382/ps/pez115

AFRC, R. F. (1989). Probiotics in man and animals. Journal of Applied Bacteriology, 66(5), 365-378. https://doi.org/10.1111/jam.1989.66.issue-5

Akbaryan, M., Mahdavi, A., Jebelli-Javan, A., Staji, H., \& Darabighane, B. (2019). A comparison of the effects of resistant starch, fructooligosaccharide, and zinc bacitracin on cecal short-chain fatty acids, cecal microflora, intestinal morphology, and antibody titer against Newcastle disease virus in broilers. Comparative Clinical Pathology, 28(3), 661-667. https://doi.org/10.1007/s00580-019-02936-9

Al-Khalaifah, H. S. (2018). Benefits of probiotics and/or prebiotics for antibiotic-reduced poultry. Poultry Science, 97(11), 3807-3815. https://doi.org/10.3382/ps/pey160

Alagawany, M., Abd El-Hack, M. E., Farag, M. R., Sachan, S., Karthik, K., \& Dhama, K. (2018). The use of probiotics as eco-friendly alternatives for antibiotics in poultry nutrition. Environmental Science and Pollution Research, 25(11), 10611-10618. https://doi.org/10.1007/s11356-018-1687-X

Alavi, S. A. N., Zakeri, A., Kamrani, B., \& Pourakbari, Y. (2012). Effect of prebiotics, probiotics, acidfire, growth promoter antibiotics and synbiotic on humural immunity of broiler chickens. Global Veterinaria, 8(6), 612-617. 
Alloui, M. N., Szczurek, W., \& Światkiewicz, S. (2013). The usefulness of prebiotics and probiotics in modern poultry nutrition: A review. Annals of Animal Science, 13(1), 17-32. https://doi.org/10.2478/v10220-012-0055-x

Antonialli, R. (2013). Efeito de ligantes de receptores semelhantes a Toll na resposta imune induzidas por antígenos direcionados ao DEC205 e DCIR2. Universidade de São Paulo.

Atabaigi Elmi, V., Moradi, S., Ghazi, S., \& Rahimi, M. (2020). Effects of Lactobacillus acidophilus and natural antibacterials on growth performance and Salmonella colonization in broiler chickens challenged with Salmonella enteritidis. Livestock Science, 233(January), 103948. https://doi.org/10.1016/j.livsci.2020.103948

Barbosa, T. M., Serra, C. R., La Ragione, R. M., Woodward, M. J., \& Henriques, A. O. (2005). Screening for Bacillus Isolates in the Broiler Gastrointestinal Tract. Applied and Environmental Microbiology, 71(2), 968-978. https://doi.org/10.1128/AEM.71.2.968-978.2005

Bengmark, S. (2005). Bioecologic control of the gastrointestinal tract: The role of flora and supplemented probiotics and synbiotics. Gastroenterology Clinics of North America, 34(3), 413-436. https://doi.org/10.1016/j.gtc.2005.05.002

Bilal, M., Si, W., Barbe, F., Chevaux, E., Sienkiewicz, O., \& Zhao, X. (2020). Effects of novel probiotic strains of Bacillus pumilus and Bacillus subtilis on production, gut health, and immunity of broiler chickens raised under suboptimal conditions. Poultry Science, 100(3), 100871. https://doi.org/10.1016/j.psj.2020.11.048

Bindels, L. B., Delzenne, N. M., Cani, P. D., \& Walter, J. (2015). Towards a more comprehensive concept for prebiotics. Nature Reviews: Gastroenterology and Hepatology, 12(5), 303-310. https://doi.org/10.1038/nrgastro.2015.47

Bovo, F., Franco, L. T., Kobashigawa, E., Rottinghaus, G. E., Ledoux, D. R., \& Oliveira, C. A. F. (2015). Efficacy of beer fermentation residue containing Saccharomyces cerevisiae cells for ameliorating aflatoxicosis in broilers. Poultry Science, 94(5), 934-942. https://doi.org/10.3382/ps/pev067

Bunesova, V., Vlkova, E., Rada, V., Killer, J., \& Musilova, S. (2014). Bifidobacteria from the gastrointestinal tract of animals: differences and similarities. Beneficial Microbes, 5(4), 377-388. https://doi.org/10.3920/BM2013.0081

Butta, H., Sardana, R., Vaishya, R., Singh, K. N., \& Mendiratta, L. (2017). Bifidobacterium: An emerging clinically significant metronidazole-resistant anaerobe of mixed pyogenic infections. Cureus, 9(4), 4-9. https://doi.org/10.7759/cureus.1134

BRASIL. 2015. Ministério da Agricultura, Pecuária e Abastecimento/Secretaria de Defesa Agropecuária. Instrução Normativa $n^{\circ} 44$, de 15 de dezembro de 2015: Regulamento técnico sobre aditivos para produtos destinados à alimentação animal.

BRASIL. 2020. Ministério da Agricultura, Pecuária e Abastecimento/Secretaria de Defesa Agropecuária. Instrução Normativa ${ }^{\circ} 1$, de 13 de janeiro de 2020 : Proibição em território nacional de aditivos melhoradores de desempenho que contenham antimicrobianos classificados como importantes na medicina humana.

Carr, F. J., Chill, D., \& Maida, N. (2002). The lactic acid bacteria: A literature survey. Critical Reviews in Microbiology, 28(4), 281-370. https://doi.org/10.1080/1040-840291046759

Castañeda, C. D., Dittoe, D. K., Wamsley, K. G. S., McDaniel, C. D., Blanch, A., Sandvang, D., \& Kiess, A. S. (2020). In ovo inoculation of an Enterococcus faecium-based product to enhance broiler hatchability, live performance, and intestinal morphology. Poultry Science, 99(11), 6163-6172. https://doi.org/10.1016/j.psj.2020.08.002

Castanon, J. I. R. 2007. History of the use of antibiotic as growth promoters in european poultry feeds. Poultry Science, 86(11), 2466-2471.

Cheng, G., Dai, M., Ahmed, S., Hao, H., Wang, X., \& Yuan, Z. (2016). Antimicrobial drugs in fighting against antimicrobial resistance. Frontiers in Microbiology, 7(APR), 1-11. https://doi.org/10.3389/fmicb.2016.00470

Corrigan, A., De Leeuw, M., Penaud-Frézet, S., Dimova, D., \& Murphya, R. A. (2015). Phylogenetic and functional alterations in bacterial community compositions in broiler ceca as a result of mannan oligosaccharide supplementation. Applied and Environmental Microbiology, 81(10), 3460-3470. https://doi.org/10.1128/AEM.04194-14

Crisol-Martínez, E., Stanley, D., Geier, M. S., Hughes, R. J., \& Moore, R. J. (2017). Understanding the mechanisms of zinc bacitracin and avilamycin on animal production: linking gut microbiota and growth performance in chickens. Applied Microbiology and Biotechnology, 101(11), 4547-4559. https://doi.org/10.1007/s00253-017-8193-9

Dean, S. N., Rimmer, M. A., Turner, K. B., Phillips, D. A., Caruana, J. C., Hervey, W. J., Leary, D. H., \& Walper, S. A. (2020). Lactobacillus acidophilus membrane vesicles as a vehicle of bacteriocin delivery. Frontiers in Microbiology, 11(April), 1-14. https://doi.org/10.3389/fmicb.2020.00710

Deleu, M., Paquot, M., \& Nylander, T. (2008). Effect of fengycin, a lipopeptide produced by Bacillus subtilis, on model biomembranes. Biophysical Journal, 94(7), 2667-2679. https://doi.org/10.1529/biophysj.107.114090

Diaz, T. G., Branco, A. F., Jacovaci, F. A., Jobim, C. C., Daniel, J. L. P., Bueno, A. V. I., \& Ribeiro, M. G. (2018). Use of live yeast and mannan-oligosaccharides in grain-based diets for cattle: Ruminal parameters, nutrient digestibility, and inflammatory response. PLOS ONE, 13(11), 1-15. https://doi.org/10.1371/journal.pone.0207127

Didari, T., Solki, S., Mozaffari, S., Nikfar, S., \& Abdollahi, M. (2014). A systematic review of the safety of probiotics. Expert Opinion on Drug Safety, 13(2), 227-239. https://doi.org/10.1517/14740338.2014.872627

El-Moneim, A. E. M. E. A., El-Wardany, I., Abu-Taleb, A. M., Wakwak, M. M., Ebeid, T. A., \& Saleh, A. A. (2019). Assessment of in ovo administration of Bifidobacterium bifidum and Bifidobacterium longum on performance, ileal histomorphometry, blood hematological, and biochemical parameters of broilers. Probiotics and Antimicrobial Proteins, 12(2), 439-450. https://doi.org/10.1007/s12602-019-09549-2 
Elghandour, M. M. Y., Tan, Z. L., Abu Hafsa, S. H., Adegbeye, M. J., Greiner, R., Ugbogu, E. A., Cedillo Monroy, J., \& Salem, A. Z. M. (2019). Saccharomyces cerevisiae as a probiotic feed additive to non and pseudo-ruminant feeding: a review. Journal of Applied Microbiology, 128(3), 658-674. https://doi.org/10.1111/jam.14416

Elshaghabee, F. M. F., Rokana, N., Gulhane, R. D., Sharma, C., \& Panwar, H. (2017). Bacillus as potential probiotics: Status, concerns, and future perspectives. Frontiers in Microbiology, 8(AUG), 1-15. https://doi.org/10.3389/fmicb.2017.01490

Estrada, A., Wilkie, D. C., \& Drew, M. (2001). Administration of Bifidobacterium bifidum to chicken broilers reduces the number of carcass condemnations for cellulitis at the abattoir. Journal of Applied Poultry Research, 10(4), 329-334. https://doi.org/10.1093/japr/10.4.329

FAO. 2016. Probiotics in animal nutrition. Physiological reviews, 34(1), 1 -108.

FDA. 2018. Antimicrobials Sold or Distributed for Use in Food-Producing Animals. Center for Veterinary Medicine 7(0) 1-25.

Feitosa, T. J. de O., Silva, C. E. da, Souza, R. G. de, Lima, C. D. S., Gurgel, A. de C., Oliveira, L. L. G. de, Nóbrega, J. G. S. da, Carvalho Júnior, J. E. M. de, Melo, F. de O. de, Santos, W. B. M. dos, Feitoza, T. de O., Costa, T. F., Brandão, P. A., \& Minafra, C. S. (2020). Intestinal microbiota of poultry: bibliographic review. Research, Society and Development, 9(5), e42952779. https://doi.org/10.33448/rsd-v9i5.2779

Figueira, S. V. (2013). Microbiota intestinal das aves de produção [Universidade Federal de Goiás]. http://www.conhecer.org.br/enciclop/2014a/AGRARIAS/microbiota.pdf

Fiore, E., Van Tyne, D., \& Gilmore, M. S. (2019). Pathogenicity of Enterococci. Microbiology Spectrum, 7(4), 189-211. https://doi.org/10.1128/microbiolspec.GPP3-0053-2018

Forte, C., Acuti, G., Manuali, E., Casagrande Proietti, P., Pavone, S., Trabalza-Marinucci, M., Moscati, L., Onofri, A., Lorenzetti, C., \& Franciosini, M. P. (2016). Effects of two different probiotics on microflora, morphology, and morphometry of gut in organic laying hens. Poultry Science, 95(11), 2528-2535. https://doi.org/10.3382/ps/pew164

Forte, C., Manuali, E., Abbate, Y., Papa, P., Vieceli, L., Tentellini, M., Trabalza-Marinucci, M., \& Moscati, L. (2018). Dietary Lactobacillus acidophilus positively influences growth performance, gut morphology, and gut microbiology in rurally reared chickens. Poultry Science, 97(3), 930-936. https://doi.org/10.3382/ps/pex396

Gadde, U., Kim, W. H., Oh, S. T., \& Lillehoj, H. S. (2017). Alternatives to antibiotics for maximizing growth performance and feed efficiency in poultry: A review. Animal Health Research Reviews, 18(1), 26-45. https://doi.org/10.1017/S1466252316000207

Gao, Z., Wu, H., Shi, L., Zhang, X., Sheng, R., Yin, F., \& Gooneratne, R. (2017). Study of Bacillus subtilis on growth performance, nutrition metabolism and intestinal microflora of 1 to $42 \mathrm{~d}$ broiler chickens. Animal Nutrition, 3(2), 109-113. https://doi.org/10.1016/j.aninu.2017.02.002

García-Solache, M., \& Rice, L. B. (2019). The Enterococcus: a Model of Adaptability to Its Environment. Clinical Microbiology Reviews, 32(2), 1-28. https://doi.org/10.1128/CMR.00058-18

Gibson, G. R., \& Roberfroid, M. B. (1995). Dietary modulation of the human colonic microbiota: Introducing the concept of prebiotics. Journal of Nutrition, 125(6), 1401-1412. https://doi.org/10.1093/jn/125.6.1401

Goldstein, E. J. C., Tyrrell, K. L., \& Citron, D. M. (2015). Lactobacillus species: Taxonomic complexity and controversial susceptibilities. Clinical Infectious Diseases, 60(Suppl 2), S98-S107. https://doi.org/10.1093/cid/civ072

Gomes, A. M. P., \& Malcata, F. X. (1999). Bifidobacterium spp. and Lactobacillus acidophilus: biological, biochemical, technological and therapeutical properties relevant for use as probiotics. Trends in Food Science \& Technology, 10(4-5), 139-157. https://doi.org/10.1016/S0924-2244(99)00033-3

Gonzales, E., Mello, H. H. D. C., \& Café, M. B. (2012). Uso de antibióticos promotores de crescimento na alimentação e produção animal. Revista UFG, 13, 48-53. https://www.proec.ufg.br/up/694/o/13_07.pdf

Grant, A., Gay, C. G., \& Lillehoj, H. S. (2018). Bacillus spp . as direct-fed microbial antibiotic alternatives to enhance growth, immunity, and gut health in poultry. Avian Pathology, 47(4), 339-351. https://doi.org/10.1080/03079457.2018.1464117

Hanchi, H., Mottawea, W., Sebei, K., \& Hammami, R. (2018). The genus Enterococcus: Between probiotic potential and safety concerns-an update. Frontiers in Microbiology, 9(AUG), 1-16. https://doi.org/10.3389/fmicb.2018.01791

Hancock, R. E. W., \& Chapple, D. S. (1999). Peptide Antibiotics. Antimicrobial Agents and Chemotherapy, 43(6), 1317-1323. https://doi.org/10.1128/AAC.43.6.1317

Hegarty, J. W., Guinane, C. M., Ross, R. P., Hill, C., \& Cotter, P. D. (2017). Lack of heterogeneity in bacteriocin production across a selection of commercial probiotic products. Probiotics and Antimicrobial Proteins, 9(4), 459-465. https://doi.org/10.1007/s12602-017-9326-2

Iannitti, T., \& Palmieri, B. (2010). Therapeutical use of probiotic formulations in clinical practice. Clinical Nutrition, 29(6), 701-725. https://doi.org/10.1016/j.clnu.2010.05.004

Jha, R., Das, R., Oak, S., \& Mishra, P. (2020). Probiotics (Direct-fed microbials) in poultry nutrition and their effects on nutrient utilization, growth and laying performance, and gut health: A systematic review. In Animals (Vol. 10, Número 10, p. 1-19). https://doi.org/10.3390/ani10101863

Khan, H., Flint, S., \& Yu, P.-L. (2010). Enterocins in food preservation. International Journal of Food Microbiology, 141(1-2), 1-10. https://doi.org/10.1016/j.ijfoodmicro.2010.03.005

Klaenhammer, T. R., \& Kullen, M. J. (1999). Selection and design of probiotics. International Journal of Food Microbiology, 50(1-2), 45-57. https://doi.org/10.1016/S0168-1605(99)00076-8 
Kuritza, L. N., Westphal, P., \& Santin, E. (2014). Probiotics on poultry production. Ciência Rural, 44(8), 1457-1465. https://doi.org/10.1590/0103$8478 \mathrm{cr} 20120220$

Lan, R. X., Lee, S. I., \& Kim, I. H. (2017). Effects of Enterococcus faecium SLB 120 on growth performance, blood parameters, relative organ weight, breast muscle meat quality, excreta microbiota shedding, and noxious gas emission in broilers. Poultry Science, 96(9), 3246-3253. https://doi.org/10.3382/ps/pex101

Leahy, S. C., Higgins, D. G., Fitzgerald, G. F., \& Sinderen, D. (2005). Getting better with bifidobacteria. Journal of Applied Microbiology, 98(6), 1303-1315. https://doi.org/10.1111/j.1365-2672.2005.02600.x

Lebreton, F., Willems, R. J. L., \& Gilmore, M. S. (2014). Enterococcus diversity, origins in nature, and gut colonization. Enterococci: From Commensals to Leading Causes of Drug Resistant Infection, 1-59. http://www.ncbi.nlm.nih.gov/pubmed/24649513

Lee, H., \& Kim, H. Y. (2011). Lantibiotics, class I Bacteriocins from the genus Bacillus. Journal of Microbiology and Biotechnology, 21(3), 229-235. https://doi.org/10.4014/jmb.1010.10017

Lee, J.-H., \& O'Sullivan, D. J. (2010). Genomic insights into bifidobacteria. Microbiology and Molecular Biology Reviews, 74(3), 378-416. https://doi.org/10.1128/MMBR.00004-10

Lemos, M. J. de, Calixto, L. F. L., Torres-Cordido, K. A. A., \& Reis, T. L. (2016). Uso de aditivo alimentar equilibrador da flora intestinal em aves de corte e de postura. Arquivos do Instituto Biológico, 83(0), 1-7. https://doi.org/10.1590/1808-1657000862014

Li, Z., Wang, W., Liu, D., \& Guo, Y. (2018). Effects of Lactobacillus acidophilus on the growth performance and intestinal health of broilers challenged with Clostridium perfringens. Journal of Animal Science and Biotechnology, 9(1), 25. https://doi.org/10.1186/s40104-018-0243-3

Lilly, D. M., \& Stillwell, R. H. (1965). Probiotics: Growth-promoting factors produced by microorganisms. Science, 147(3659), 747-748. https://doi.org/10.1126/science.147.3659.747

Luoma, A., Markazi, A., Shanmugasundaram, R., Murugesan, G. R., Mohnl, M., \& Selvaraj, R. (2017). Effect of synbiotic supplementation on layer production and cecal Salmonella load during a Salmonella challenge. Poultry Science, 96(12), 4208-4216. https://doi.org/10.3382/ps/pex251

Macedo, L. L., Vimercati, W. C., \& Araújo, C. da S. (2020). Fruto-oligossacarídeos: aspectos nutricionais, tecnológicos e sensoriais. Brazilian Journal of Food Technology, 23, 1-9. https://doi.org/10.1590/1981-6723.08019

Maget-Dana, R., \& Peypoux, F. (1994). Iturins, a special class of pore-forming lipopeptides: biological and physicochemical properties. Toxicology, 87(1-3), 151-174. https://doi.org/10.1016/0300-483X(94)90159-7

Mannu, L., Paba, A., Daga, E., Comunian, R., Zanetti, S., Duprè, I., \& Sechi, L. A. (2003). Comparison of the incidence of virulence determinants and antibiotic resistance between Enterococcus faecium strains of dairy, animal and clinical origin. International Journal of Food Microbiology, 88(2-3), 291-304. https://doi.org/10.1016/S0168-1605(03)00191-0

Markowiak, P., \& Śliżewska, K. (2018). The role of probiotics, prebiotics and synbiotics in animal nutrition. Gut Pathogens, 10(1), 21. https://doi.org/10.1186/s13099-018-0250-0

Matur, E., Ergul, E., Akyazi, I., Eraslan, E., \& Cirakli, Z. T. (2010). The effects of Saccharomyces cerevisiae extract on the weight of some organs, liver, and pancreatic digestive enzyme activity in breeder hens fed diets contaminated with aflatoxins. Poultry Science, 89(10), 2213-2220. https://doi.org/10.3382/ps.2010-00821

Menconi, A., Wolfenden, A. D., Shivaramaiah, S., Terraes, J. C., Urbano, T., Kuttel, J., Kremer, C., Hargis, B. M., \& Tellez, G. (2011). Effect of lactic acid bacteria probiotic culture for the treatment of Salmonella enterica serovar Heidelberg in neonatal broiler chickens and Turkey poults. Poultry Science, 90(3), 561-565. https://doi.org/10.3382/ps.2010-01220

Mesquita, A. R. C. de, Silveira, L. P. da M., Cruz Filho, I. J. Da, Lima, V. F. de, Silveira Filho, V. D. M., Araujo, A. A., Silva, T. L. Da, Araújo, K. D. F., \& Macedo, L. D. S. (2017). Metabolism and physiology of Lactobacilli: a review. Journal of Environmental Analysis and Progress, 2(2), 125-136. https://doi.org/10.24221/jeap.2.2.2017.1202.115-124

Mohammed, A. A., Jiang, S., Jacobs, J. A., \& Cheng, H. W. (2019). Effect of a synbiotic supplement on cecal microbial ecology, antioxidant status, and immune response of broiler chickens reared under heat stress. Poultry Science, 98(10), 4408-4415. https://doi.org/10.3382/ps/pez246

Morales-Lopez, R., \& Brufau, J. (2013). Immune-modulatory effects of dietary Saccharomyces cerevisiae cell wall in broiler chickens inoculated with Escherichia coli lipopolysaccharide. British Poultry Science, 54(2), 247-251. https://doi.org/10.1080/00071668.2013.782386

O'Donnell, J. A., Gelone, S. P., \& Safdar, A. (2014). Topical Antibacterials. In Mandell, Douglas, and Bennett's Principles and Practice of Infectious Diseases (Eighth Edi, Vol. 1, p. 452-462). Elsevier Inc. https://doi.org/10.1016/B978-1-4557-4801-3.00037-0

Ozogul, F., \& Hamed, I. (2016). Lactic Acid Bacteria: Lactobacillus spp.: Lactobacillus acidophilus. In Reference Module in Food Science (p. 1-10). Elsevier. https://doi.org/10.1016/B978-0-08-100596-5.00852-0

Palma, M. L., Zamith-Miranda, D., Martins, F. S., Bozza, F. A., Nimrichter, L., Montero-Lomeli, M., Marques, E. T. A., \& Douradinha, B. (2015). Probiotic Saccharomyces cerevisiae strains as biotherapeutic tools: is there room for improvement? Applied Microbiology and Biotechnology, 99(16), 6563-6570. https://doi.org/10.1007/s00253-015-6776-x

Park, S. H., Perrotta, A., Hanning, I., Diaz-Sanchez, S., Pendleton, S., Alm, E., \& Ricke, S. C. (2017). Pasture flock chicken cecal microbiome responses to prebiotics and plum fiber feed amendments. Poultry Science, 96(6), 1820-1830. https://doi.org/10.3382/ps/pew441

Pavli, V., \& Kmetec, V. (2006). Pathways of chemical degradation of polypeptide antibiotic bacitracin. Biological \& Pharmaceutical Bulletin, 29(11), 21602167. https://doi.org/10.1248/bpb.29.2160 
Pender, C. M., Kim, S., Potter, T. D., Ritzi, M. M., Young, M., \& Dalloul, R. A. (2016). In ovo supplementation of probiotics and its effects on performance and immune-related gene expression in broiler chicks. Poultry Science, 96(5), 1052-1062. https://doi.org/10.3382/ps/pew381

Penha Filho, R. A. C., Díaz, S. J. A., Fernando, F. S., Chang, Y.-F., Andreatti Filho, R. L., \& Berchieri Junior, A. (2015). Immunomodulatory activity and control of Salmonella Enteritidis colonization in the intestinal tract of chickens by Lactobacillus based probiotic. Veterinary Immunology and Immunopathology, 167(1-2), 64-69. https://doi.org/10.1016/j.vetimm.2015.06.006

Picard, C., Fioramonti, J., Francois, A., Robinson, T., Neant, F., \& Matuchansky, C. (2005). Review article: bifidobacteria as probiotic agents - physiological effects and clinical benefits. Alimentary Pharmacology and Therapeutics, 22(6), 495-512. https://doi.org/10.1111/j.1365-2036.2005.02615.x

Pourabedin, M., \& Zhao, X. (2015). Prebiotics and gut microbiota in chickens. FEMS Microbiology Letters, 362(15), fnv122. https://doi.org/10.1093/femsle/fnv122

Puppala, K. R., Ravi Kumar, V., Khire, J., \& Dharne, M. (2018). Dephytinizing and probiotic potentials of Saccharomyces cerevisiae (NCIM 3662) strain for amelioration of nutritional quality of functional foods. Probiotics and Antimicrobial Proteins, 11(2), 604-617. https://doi.org/10.1007/s12602-018-9394-y

Raghuwanshi, S., Misra, S., Sharma, R., \& Bisen, P. S. (2015). Indian perspective for probiotics : A review. Indian J Dairy Sci, $68(3), 195-205$.

Raizel, R., Santini, E., Kopper, A. M., \& Reis Filho, A. D. (2011). Effects of probiotics, prebiotics and synbiotics consumption on the human organism organism. Ciência \& Saúde, 4(2), 66-74. https://doi.org/10.15448/1983-652X.2011.2.8352

Reis, T. L., \& Vieites, F. M. (2019). Antibiótico, prebiótico, probiótico e simbiótico em rações de frangos de corte e galinhas poedeiras. Ciência Animal, 29(3), $133-147$

Ricke, S. C. (2015). Potential of fructooligosaccharide prebiotics in alternative and nonconventional poultry production systems. Poultry Science, 94(6), 14111418. https://doi.org/10.3382/ps/pev049

Ricke, Steven C., Lee, S. I., Kim, S. A., Park, S. H., \& Shi, Z. (2020). Prebiotics and the poultry gastrointestinal tract microbiome. Poultry Science, 99(2), 670677. https://doi.org/10.1016/j.psj.2019.12.018

Romero-Luna, H. E., Hernández-Sánchez, H., Ribas-Aparicio, R. M., Cauich-Sánchez, P. I., \& Dávila-Ortiz, G. (2018). Evaluation of the probiotic potential of Saccharomyces cerevisiae strain (C41) isolated from tibicos by in vitro studies. Probiotics and Antimicrobial Proteins, 11(3), 794-800. https://doi.org/10.1007/s12602-018-9471-2

Roselli, M., Finamore, A., Britti, M. S., Bosi, P., Oswald, I., \& Mengheri, E. (2005). Alternatives to in-feed antibiotics in pigs: Evaluation of probiotics, zinc or organic acids as protective agents for the intestinal mucosa. A comparison of in vitro and in vivo results. Animal Research, 54(3), 203-218. https://doi.org/10.1051/animres:2005012

Salminen, S., Bouley, C., Boutron, M.-C., Cummings, J. H., Franck, A., Gibson, G. R., Isolauri, E., Moreau, M.-C., Roberfroid, M., \& Rowland, I. (1998). Functional food science and gastrointestinal physiology and function. British Journal of Nutrition, 80(S1), S147-S171. https://doi.org/10.1079/bjn19980108

Santos, J. B. dos. (2018). Seleção de estirpes de Bacillus spp. tóxicas a Meloidogyne spp. e promotoras de crescimento vegetal. Universidade de Brasília.

Schmitt, J. A. D. (2014). Avaliação do perfil probiótico de cepas de Lactobacillus acidophilus destinados a aplicações farmacêuticas e alimentícias. Universidade Estadual do Oeste do Paraná.

Shah, N., \& Rajiv, D. (2002). Antimicrobial lactic substances including bacteriocins produced by acid bacteria. Bioscience Microflora, 21(4), 217-223.

Shang, Y., Kumar, S., Thippareddi, H., \& Kim, W. K. (2018). Effect of dietary fructooligosaccharide (FOS) supplementation on ileal microbiota in broiler chickens. Poultry Science, 97(10), 3622-3634. https://doi.org/10.3382/ps/pey131

Silva, E. N. da, \& Filho, R. L. A. (2000). Probióticos E Prebióticos Na Avicultura. Simpósio de Sanidade Avícola, 2 , 45-55.

Silva, J. D. T., Matos, A. D. S., Hada, F. H., Gravena, R. A., Marques, R. H., \& Moraes, V. M. B. (2012). Simbiótico e extratos naturais na dieta de codornas japonesas na fase de postura. Ciência Animal Brasileira, 13(1), 1-7. https://doi.org/10.5216/cab.v13i1.5547

Soccol, C. R., Vandenberghe, L. P. de S., Spier, M. R., Medeiros, A. B. P., Yamaguishi, C. T., De Dea Lindner, J., Pandey, A., \& Thomaz-Soccol, V. (2010). The potential of probiotics: A review. Food Technology and Biotechnology, 48(4), 413-434.

Sumi, C. D., Yang, B. W., Yeo, I. C., \& Hahm, Y. T. (2015). Antimicrobial peptides of the genus Bacillus: A new era for antibiotics. Canadian Journal of Microbiology, 61(2), 93-103. https://doi.org/10.1139/cjm-2014-0613

Swanson, K. S., Gibson, G. R., Hutkins, R., Reimer, R. A., Reid, G., Verbeke, K., Scott, K. P., Holscher, H. D., Azad, M. B., Delzenne, N. M., \& Sanders, M. E. (2020). The International Scientific Association for Probiotics and Prebiotics (ISAPP) consensus statement on the definition and scope of synbiotics. Nature Reviews Gastroenterology \& Hepatology, 17(11), 687-701. https://doi.org/10.1038/s41575-020-0344-2

Świątkiewicz, S., Arczewska-Włosek, A., \& Józefiak, D. (2014). Immunomodulatory efficacy of yeast cell products in poultry: a current review. World's Poultry Science Journal, 70(1), 57-68. https://doi.org/10.1017/S0043933914000051

Tabasco, R., García-Cayuela, T., Peláez, C., \& Requena, T. (2009). Lactobacillus acidophilus La-5 increases lactacin B production when it senses live target bacteria. International Journal of Food Microbiology, 132(2-3), 109-116. https://doi.org/10.1016/j.ijfoodmicro.2009.04.004

Tannock, G. W., Munro, K., Harmsen, H. J. M., Welling, G. W., Smart, J., \& Gopal, P. K. (2000). Analysis of the fecal microflora of human subjects consuming a probiotic product containing Lactobacillus rhamnosusDR20. Applied and Environmental Microbiology, 66(6), 2578-2588. https://doi.org/10.1128/AEM.66.6.2578-2588.2000 
Research, Society and Development, v. 10, n. 7, e40410716633, 2021

(CC BY 4.0) | ISSN 2525-3409 | DOI: http://dx.doi.org/10.33448/rsd-v10i7.16633

Teng, P.-Y., \& Kim, W. K. (2018). Review: Roles of prebiotics in intestinal ecosystem of broilers. Frontiers in Veterinary Science, 5(OCT), 1-18. https://doi.org/10.3389/fvets.2018.00245

Thema, K., Mlambo, V., Snyman, N., \& Mnisi, C. M. (2019). Evaluating Alternatives to Zinc-Bacitracin Antibiotic Growth Promoter in Broilers: Physiological and Meat Quality Responses. Animals, 9(12), 1160. https://doi.org/10.3390/ani9121160

Tiwari, G., Tiwari, R., Pandey, S., \& Pandey, P. (2012). Promising future of probiotics for human health: Current scenario. Chronicles of Young Scientists, 3(1), 17. https://doi.org/10.4103/2229-5186.94308

Toledo, G. S. P. de, Costa, P. T. C., Silva, L. P. da, Pinto, D., Ferreira, P., \& Poletto, C. J. (2007). Performance of broilers fed diets added of antibiotic and phytoterapic isolated or associated. Ciência Rural, 37(6), 1760-1764. https://doi.org/10.1590/S0103-84782007000600040

Wang, J., Wan, C., Shuju, Z., Yang, Z., Celi, P., Ding, X., Bai, S., Zeng, Q., Mao, X., Xu, S., Zhang, K., \& Li, M. (2021). Differential analysis of gut microbiota and the effect of dietary Enterococcus faecium supplementation in broiler breeders with high or low laying performance. Poultry Science, 100(2), 1109-1119. https://doi.org/10.1016/j.psj.2020.10.024

World Health Organization. 1997. The medical impact of antimicrobial use in food animals. WHO.

Zhang, C., Li, C. X., Shao, Q., Chen, W. B., Ma, L., Xu, W. H., Li, Y. X., Huang, S. C., \& Ma, Y. B. (2020). Effects of Glycyrrhiza polysaccharide in diet on growth performance, serum antioxidant capacity, and biochemistry of broilers. Poultry Science, 100(3), 100927. https://doi.org/10.1016/j.psj.2020.12.025

Zhang, S., Zhong, G., Shao, D., Wang, Q., Hu, Y., Wu, T., Ji, C., \& Shi, S. (2021). Dietary supplementation with Bacillus subtilis promotes growth performance of broilers by altering the dominant microbial community. Poultry Science, 100(3), 100935. https://doi.org/10.1016/j.psj.2020.12.032

Zhao, X., \& Kuipers, O. P. (2016). Identification and classification of known and putative antimicrobial compounds produced by a wide variety of Bacillales species. BMC Genomics, 17(1), 882. https://doi.org/10.1186/s12864-016-3224-y

Zheng, J., Wittouck, S., Salvetti, E., Franz, C. M. A. P., Harris, H. M. B., Mattarelli, P., O’Toole, P. W., Pot, B., Vandamme, P., Walter, J., Watanabe, K., Wuyts, S., Felis, G. E., Gänzle, M. G., \& Lebeer, S. (2020). A taxonomic note on the genus Lactobacillus: Description of 23 novel genera, emended description of the genus Lactobacillus Beijerinck 1901, and union of Lactobacillaceae and Leuconostocaceae. International Journal of Systematic and Evolutionary Microbiology, 70(4), 2782-2858. https://doi.org/10.1099/ijsem.0.004107 